Article

\title{
Squalene Epoxidase Correlates E-Cadherin Expression and Overall Survival in Colorectal Cancer Patients: The Impact on Prognosis and Correlation to Clinicopathologic Features
}

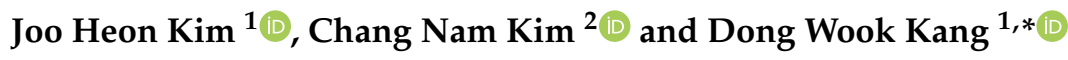 \\ 1 Department of Pathology, Eulji University Hospital, Eulji University School of Medicine, Daejeon 35233, \\ Korea; kjh2000@eulji.ac.kr \\ 2 Department of Surgery, Eulji University Hospital, Eulji University School of Medicine, Daejeon 35233, Korea; \\ kimcn@eulji.ac.kr \\ * Correspondence: astro966@gmail.com; Tel.: +82-10-8561-9895; Fax: +82-42-611-3459
}

Received: 22 April 2019; Accepted: 6 May 2019; Published: 8 May 2019

\begin{abstract}
Squalene epoxidase (SE), coded by $S Q L E$, is an important rate-limiting enzyme in the cholesterol biosynthetic pathway. Recently, the aberrant expression of SQLE, which is responsible for epithelial to mesenchymal transition (EMT), has been reported in various types of cancer. This study was undertaken to clarify the clinicopathologic implications of SE in patients with stage I to IV colorectal cancer (CRC). We also analyzed the expression patterns of SE in association with E-cadherin in a series of CRCs. We detected the cytoplasmic expression of SE in $59.4 \%$ of carcinoma samples by immunohistochemistry (IHC). There was a significant correlation between a high level of SE expression and lymphovascular (LV) invasion $(p<0.001)$, tumor budding $(p<0.001)$, invasion depth $(p=0.002)$, regional lymph node metastasis $(p<0.001)$, and pathologic TNM stage $(p<0.001)$. SE is more abundantly expressed at the invasive front, and reversely correlated with E-cadherin expression. Patients with SE-positive CRC had shorter recurrence-free survival (RFS) and poor overall survival (OS) than those with SE-negative CRC in multivariate analysis ( $p<0.001$ and $p<0.001$, respectively). These data suggest that SE can serve as a valuable biomarker for unfavorable prognosis, and as a possible therapeutic target in CRCs.
\end{abstract}

Keywords: squalene epoxidase (SE); SQLE; E-cadherin; immunohistochemistry; colorectal cancer

\section{Introduction}

Colorectal cancer (CRC) ranks fourth highest in the number of all cancer cases reported worldwide and is currently one of the leading causes of cancer-associated mortality [1,2], despite earlier detection and many accomplishments in the development of molecular-based treatment. CRC is a heterogeneous and complex disease, and its molecular mechanism of carcinogenesis is a multi-step process related to the genomic instability associated with genetic alterations [3]. Furthermore, knowledge of the invasion and metastatic process of colon cancer is still very limited. Thus, the discovery of tumor markers is highly desirable, as it would allow treatment to be tailored to individuals likely to require better-targeted therapies in clinical practice. The human squalene epoxidase (SE), coded by SQLE which maps to chromosomal 8q24.13, catalyzes the conversion of squalene to 2,3(S)-oxidosqualene in cholesterol biosynthesis and is suggested to be one of the critical rate-limiting enzymes in downstream cholesterol biosynthesis $[4,5]$. It has been exploited as a target for the development of hypocholesterolemic and antifungal agents. Since 1981, several studies have demonstrated that SQLE is deregulated in human cancers and has multifunctional roles. Studies conducted using cDNA microarrays reported the 
presence of $S Q L E$ in sets of differentially expressed transcripts in breast cancers [6] and lung squamous cell carcinoma [7]. Recent studies have shown that $S Q L E$ is differentially expressed in lung cancer [7,8], breast cancer [9,10], prostate cancer [11,12], hepatocellular carcinoma [13], and esophageal cancer [14]. $S Q L E$ overexpression or copy number variation is significantly associated with tumor progression, metastases and unfavorable outcomes in prostate cancer and breast cancer patients $[6,15,16]$. In vitro analysis showed that $S Q L E$ knockdown reduced the migration, progression, invasion, and metastasis of prostate cancer cells [11], and diminished epithelial to mesenchymal transition (EMT) in esophageal cancer [17]. Higher SQLE expression was strongly associated with increased histologic markers of angiogenesis [18]. Even though SQLE may still influence tumorigenesis and tumor progression, its intracellular function and regulation in tumor cells remain to be further investigated. To date, there is no report regarding the prognostic value of abnormal SQLE protein expression in colorectal cancer tissues. Therefore, we explored the clinicopathologic correlation and its clinical significance in CRC and correlation between SE and E-cadherin expression status in CRC.

\section{Materials and Methods}

\subsection{Case Selection}

A series of 143 cases of CRC were selected from patients who underwent surgical resection at Eulji University Hospital from 2000 to 2005. We excluded those specimens obtained from patients who received preoperative neoadjuvant chemoradiotherapy. The pertinent clinical and pathologic information was obtained from pathology reports and electronic operation records. All cases were histologically confirmed as primary colorectal adenocarcinoma, and the H\&E slides were re-examined by two independent pathologists (Kim, J.H. and Kang, D.W.). The tumor grade was classified into a low grade ( $\geq 50 \%$ of tubules) and high grade $(<50 \%$ of tubules) [19]. Tumor budding was defined as a single tumor cell or a group of up to four detached cancer cells, and classified into two grades [20-22]. The cancer recurrence was indicated as a tumor presenting at the anastomosing site, in the perineum or pelvic cavity and regional lymph nodes diagnosed by radiologic finding, colonoscopy and exploratory surgical and/or microscopic examination. Also, tumor metastasis was designated as the presence of cancer cells outside the area of surgical resection, including the lung, liver, pancreas, bone and other organs.

\subsection{Immunohistochemistry (IHC)}

For the IHC, all cases of CRC tissue with accompanying normal epithelium were fixed in 10\% buffered formalin for 24 to $48 \mathrm{~h}$ and embedded in paraffin. Immunostaining was performed on tissue sections of $4 \mu \mathrm{m}$ thickness, using IgG-rabbit polyclonal antibody against SQLE (1:100 dilution; Interchim, Montluçon, France) and mouse monoclonal antibody against E-cadherin (NCH-38, 1:100 dilution; DakoCytomation, Glostrup, Denmark) as primary antibodies. Paraffin-embedded tissue sections were deparaffinized and rehydrated through a series of xylene and graded ethanol, and autoclaved at $120^{\circ} \mathrm{C}$ for $10 \mathrm{~min}$ with $10 \mathrm{mM} / \mathrm{L}$ sodium citrate buffer ( $\mathrm{pH}$ 6.0). IHC conditions for SE and E-cadherin were optimized according to the manufacturers' instructions. The slide sections were incubated with the primary antibodies for $90 \mathrm{~min}$ and stained with 3,3'-diaminobenzidine as the substrate using an EnVision-HRP kit (DakoCytomation, Glostrup, Denmark). Negative controls were obtained by using an irrelevant mouse IgG of the same isotype. All slides were counterstained for 1 min using Mayer's hematoxylin and then mounted.

\subsection{Assessment of Immunohistochemical Staining}

To evaluate the immunohistochemical expression of SE and E-cadherin in association with the various clinicopathologic parameters, the immunoreactivity of both SE and E-cadherin were analyzed in a semi-quantitative manner by two independent pathologists, who were blinded to outcome. Immunoreactivity for SE and E-cadherin was observed primarily in the cytoplasm and 
cytoplasmic membrane of the normal colonic epithelium and tumor cells, respectively. The intensity of immunohistochemical stain was scored as 0,1 and 2 (0: no or less weak staining than normal colonic epithelium, 1: stained similar to the normal colonic epithelium, and 2: stronger staining than the normal colonic epithelium). The proportion of positive tumor cells was scaled as 1 to 4 (1: $0-24 \%$ of tumor cells, 2: $25-49 \%$ of tumor cells, $3: 50-74 \%$ of tumor cells and $4: 75-100 \%$ of tumor cells, respectively) [23]. To evaluate the statistical analysis between $\mathrm{SE}$ and E-cadherin expression and the clinicopathologic parameters, the cutoff value ( $25 \%$ of tumor cells showing a strong immunoreactivity than normal colonic epithelium) was used to distinguish between the low expression $(<25 \%$ of tumor cells) and high expression ( $>25 \%$ of tumor cells). Conflicting cases were re-examined, and consensuses were reached.

\subsection{Statistical Analysis of Prognostic Parameters}

We performed statistical analyses using the SPSS software package (ver. 21; SPSS Inc., Chicago, IL, USA). The correlation between SE and the various clinicopathologic parameters was analyzed with Pearson's chi-square test or Fisher's exact test and one-way ANOVA test. To evaluate the statistical significance, recurrence-free survival (RFS) was defined as the time from the date of surgical operation to the first date of recurrence, or the date of the last follow-up. Similarly, overall survival (OS) was defined as the duration from the date of surgery to the date of death, or the date of the last follow-up. The mean follow-up duration for all of the patients was 65.0 months, ranging from 0.6 to 184.9 months. Using the Kaplan-Meier (product-limit) test, the RFS curve, and the OS curve were formulated. Multivariate analysis for OS and RFS was also performed with Cox proportional hazard regression analysis. To examine the statistical correlation between the differences in survival distribution, the log-rank test was used. In all statistical analyses, $p$-values less than 0.05 were considered statistically significant.

\subsection{Ethical Permission}

The Institutional Review Board of Eulji University Hospital approved the study protocol and provided all necessary ethical permission (IRB File No. 2019-02-014-001).

\section{Results}

\subsection{Association of SE and E-Cadherin Expression Status with Clinicopathologic Characteristics}

Expression levels of SE and E-cadherin were evaluated by immunohistochemical analysis. The high expression of SE and E-cadherin expression at the invasive front was observed in 85 (59.4\%) and 17 $(11.9 \%)$ of the 143 patients, respectively. SE immunoreactivity was found primarily in the cytoplasm of the cancer cells. E-cadherin staining was seen predominantly in the cytoplasmic membrane, as previous studies have shown. In normal colonic epithelium, immunoreactivity for SE was mostly none or weak. Expression levels of SE were highest in the tumor invasive front cluster, lower in the tumor center, and lowest in normal epithelium. In contrast, expression levels of E-cadherin increased significantly in normal epithelium and decreased from tumor center to tumor invasion front clusters. Figure 1 shows representative expression patterns of SE and E-cadherin in CRC. The clinical and pathologic characteristics of the 143 CRC patients who underwent surgical resection are summarized in Table 1. The median age of the CRC patients at the time of surgical operation was 62.2 years $(\mathrm{M}: \mathrm{F}=75: 68$, ranging: 28-86 years) and the median tumor size was $5.2 \mathrm{~cm}$ (range: $0.8-12.0 \mathrm{~cm}$ ) in maximum tumor diameter. We analyzed whether the SE expression level was associated with clinicopathologic factors potentially predictive of prognosis. Patients with high SE expression at the invasive front showed a significantly greater presence of lymphovascular (LV) invasion, deeper invasion depth ( $\mathrm{pT}$ stage), more frequent regional lymph node metastasis ( $\mathrm{pN}$ stage), and more advanced tumor staging (pTNM stage) than in those with low SE expression levels. We also evaluated the association between E-cadherin expression levels and these variables. A statistically reverse correlation was also 
found between E-cadherin expression status and SE expression level $(p<0.001)$ (Figure 2). Specifically, of the 85 cases exhibiting a high level of SE expression at the invasive front, a total of 71 cases $(83.5 \%)$ showed decreased membranous immunoreactivity of E-cadherin. Of the 58 cases with a low level of SE expression, only 3 cases (5.2\%) revealed increased E-cadherin expression. In addition, of the 60 cases $(42.0 \%)$ with high expression of SE in the tumor center, 47 cases $(73.8 \%)$ revealed the loss of immunoreactivity of E-cadherin. The immunohistochemical comparison between SE and E-cadherin expression in the invasive front and tumor center is summarized in Table 2.

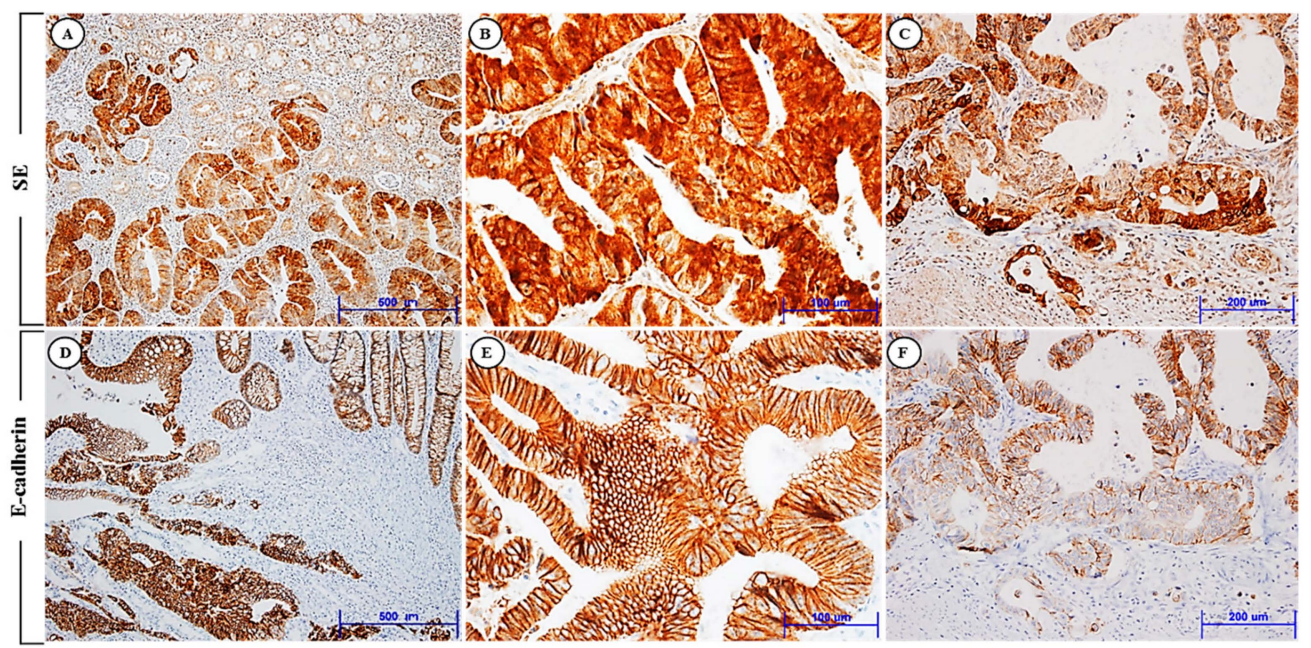

Figure 1. Immunohistochemical expression of SE (A-C) and E-cadherin (D-F) in human CRC. (A) Tumor cells show high SE expression, but no or weak expression of SE in the normal colonic epithelium $(\times 100)$. (B) Tumor cells reveal strong SE expression primarily in the cytoplasm of the tumor cells $(\times 400)$. (C) SE expression is highly increased in the tumor cells of the invasive front $(\times 200)$. (D) Strong immunoreactivity of E-cadherin in the normal colonic epithelium and tumor cells $(\times 100)$. (E) E-cadherin is highly expressed, predominantly in the membrane of the tumor cells $(\times 400)$. (F) E-cadherin expression decreases from tumor center to tumor invasion front clusters $(\times 200)$. SE and E-cadherin show different immunohistochemical expression in the invasion front of human CRC.

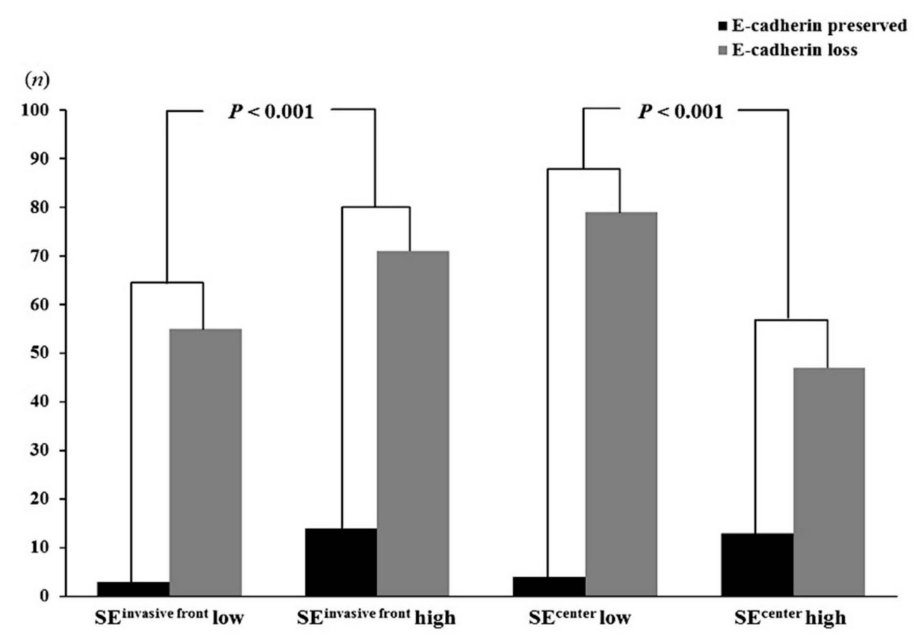

Figure 2. Immunohistochemical relationship between SE and E-cadherin in CRC. The expression pattern of SE is reversely correlated with E-cadherin expression in both the invasive front and the tumor center of CRC $(p<0.001)$. 
Table 1. Clinicopathologic variables and the expression status of SE at the invasive front in CRC.

\begin{tabular}{|c|c|c|c|c|c|c|}
\hline \multirow{3}{*}{ Characteristics } & \multirow{3}{*}{ Total } & \multicolumn{4}{|c|}{ SE Expression } & \multirow{3}{*}{$p$} \\
\hline & & \multicolumn{2}{|c|}{ Negative/Low } & \multicolumn{2}{|c|}{ High } & \\
\hline & & $n=58$ & $\%$ & $n=85$ & $\%$ & \\
\hline \multicolumn{7}{|l|}{ Age (years) } \\
\hline$<50$ & 26 & 10 & 17.2 & 16 & 18.8 & $0.830 *$ \\
\hline$\geq 50$ & 117 & 48 & 82.8 & 69 & 81.2 & \\
\hline \multicolumn{7}{|l|}{ Gender } \\
\hline Female & 68 & 33 & 48.5 & 35 & 33.3 & $0.088^{*}$ \\
\hline Male & 75 & 25 & 51.5 & 50 & 66.7 & \\
\hline \multicolumn{7}{|l|}{ Site } \\
\hline $\begin{array}{l}\text { Right/Transverse } \\
\text { colon }\end{array}$ & 34 & 16 & 27.6 & 18 & 21.2 & $0.426^{*}$ \\
\hline Left colon and rectum & 109 & 42 & 72.4 & 67 & 78.8 & \\
\hline Size & & & & & & $0.391 *$ \\
\hline$<5 \mathrm{~cm}$ in diameter & 60 & 27 & 46.6 & 33 & 38.8 & \\
\hline$\geq 5 \mathrm{~cm}$ in diameter & 83 & 31 & 53.4 & 52 & 61.2 & \\
\hline Grade & & & & & & 1.000 * \\
\hline Low & 111 & 45 & 77.6 & 66 & 77.6 & \\
\hline High & 32 & 13 & 22.4 & 19 & 22.4 & \\
\hline LV invasion & & & & & & $<0.001$ * \\
\hline Not identified & 39 & 26 & 44.8 & 13 & 15.3 & \\
\hline Present & 104 & 32 & 55.2 & 72 & 64.7 & \\
\hline Tumor border & & & & & & 0.378 * \\
\hline Pushing & 13 & 7 & 12.1 & 6 & 7.1 & \\
\hline Infiltrating & 130 & 51 & 87.9 & 79 & 92.9 & \\
\hline Tumor budding & & & & & & $<0.001$ * \\
\hline Low & 36 & 26 & 44.8 & 10 & 11.8 & \\
\hline High & 107 & 32 & 55.2 & 75 & 88.2 & \\
\hline Invasion depth & & & & & & $0.002^{+}$ \\
\hline pT1 & 5 & 4 & 6.9 & 1 & 1.2 & \\
\hline pT2 & 21 & 15 & 25.9 & 6 & 7.1 & \\
\hline pT3 & 105 & 36 & 62.1 & 69 & 81.2 & \\
\hline pT4 & 12 & 3 & 5.2 & 9 & 10.6 & \\
\hline LN metastasis & & & & & & $<0.001 \ddagger$ \\
\hline $\mathrm{pN} 0$ & 67 & 37 & 63.8 & 30 & 35.3 & \\
\hline $\mathrm{pN} 1$ & 23 & 11 & 19.0 & 12 & 14.1 & \\
\hline $\mathrm{pN} 2$ & 53 & 10 & 17.2 & 43 & 50.6 & \\
\hline Distant metastasis & & & & & & $0.005^{+}$ \\
\hline M0 & 121 & 55 & 94.8 & 66 & 77.6 & \\
\hline M1 & 22 & 3 & 5.2 & 19 & 22.4 & \\
\hline TNM stage & & & & & & $<0.001 \ddagger$ \\
\hline I & 21 & 16 & 27.6 & 5 & 5.9 & \\
\hline II & 45 & 21 & 36.2 & 24 & 28.2 & \\
\hline III & 55 & 18 & 31.0 & 37 & 43.5 & \\
\hline IV & 22 & 3 & 5.2 & 19 & 22.4 & \\
\hline
\end{tabular}

SE, squalene epoxidase; LV, lymphovascular invasion; LN, lymph node. * $p$ values were estimated by Pearson's chi-square test; ${ }^{+} p$ values were estimated by Fisher's exact test; ${ }^{\ddagger} p$ values were estimated by one-way ANOVA test; $p<0.05$ are highlighted in bold. 
Table 2. Comparison of expression between SE and E-cadherin in CRC.

\begin{tabular}{|c|c|c|c|}
\hline \multirow{2}{*}{ SE Expression } & \multicolumn{2}{|c|}{ E-Cadherin Expression } & \multirow{2}{*}{$p$-Value } \\
\hline & High $(n=17)(\%)$ & Low/Negative $(n=126)(\%)$ & \\
\hline \multicolumn{4}{|l|}{ Invasive front } \\
\hline Low/negative $(n=58)$ & $3(5.2)$ & $55(94.8)$ & \multirow{2}{*}{$<0.001$} \\
\hline $\operatorname{High}(n=85)$ & $14(16.5)$ & $71(83.5)$ & \\
\hline \multicolumn{4}{|l|}{ Tumor center } \\
\hline Low/negative, $(n=83)$ & $4(4.8)$ & 79 (95.2) & \multirow{2}{*}{$<0.001$} \\
\hline High, $(n=60)$ & $13(21.7)$ & $47(73.8)$ & \\
\hline
\end{tabular}

\subsection{High SE Expression at the Invasive Front Correlates with RFS and OS}

We performed a univariate analysis of whether the expression status of SE correlates with RFS and OS. Forty-one (28.6\%) patients presented with cancer recurrence during follow-up and $62(43.3 \%)$ patients died of CRC with or without metastasis. Seven (4.9\%) patients died of unknown causes, $11(7.6 \%)$ patients were alive with local recurrence and/or distant metastasis, and $63(44.0 \%)$ patients remained alive and recurrence-free. The Kaplan-Meier analysis showed that there was a significant correlation between high SE expression and reduced RFS ( $p<0.001)$ (Figure 3A). RFS was shorter in patients with high expression levels of SE, being only a mean duration of 53.60 months (95\% confidence interval (CI), 39.298-67.909), whereas it was longer in those patients with low levels of SE expression, being a mean duration of 143.36 months (95\% CI, 124.453-162.270). There was also a significant correlation between high SE expression and shorter OS $(p<0.001)$. SE expression status significantly split the cumulative OS curves of patients (Figure 3B). While the median OS for CRC patients with a high level of SE expression was 70.8 months (95\% CI, 55.603-85.921), the median OS of CRC patients with a low SE expression level was increased to 157.0 months (95\% CI, 141.161-172.760). A multivariate analysis was also done to assess the predictive value of SE expression for RFS and OS by adjusting other potentially prognostic parameters. In a multivariate Cox regression analysis, SE expression status was an independent prognostic factor significantly associated with RFS with a $p$-value of $<0.001$. The relative risk (RR) of tumor recurrence for patients with a high SE expression level was 3.647 (95\% CI: 1.912-6.955). A high level of SE expression was also predictive of reduced OS $(p<0.001)$. The RR of death in patients with a high level of SE expression was more than three times greater (RR: 3.976; 95\% CI: 1.894-8.347) than in those with low SE expression levels. In addition to SE expression status, statistically significant clinicopathologic factors that were correlated with OS were invasion depth $(p=0.030)$, and distant metastasis $(p<0.001)$. Table 3 summarizes the results from the Cox proportional hazards analysis.

A

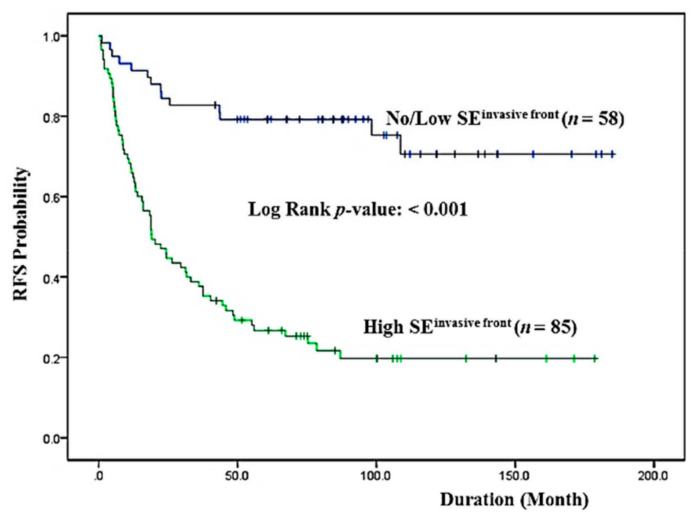

B

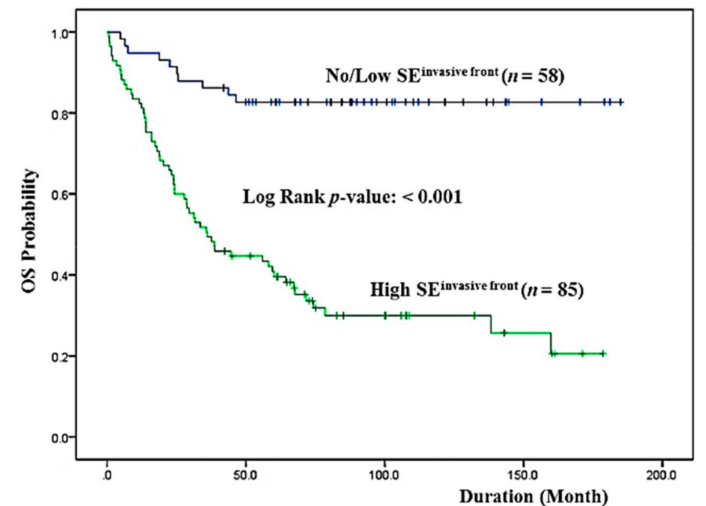

Figure 3. Kaplan-Meier survival analysis by SE expression status at the invasive front. (A) Cumulative RFS differences between patients with high and low SE expression. (B) Cumulative OS differences between patients with high and low SE expression. The $p$-value was obtained using the log-rank test of the differences. RFS: recurrence-free surviva; OS: overall survival. 
Table 3. Multivariate analysis for RFS and OS in CRC.

\begin{tabular}{|c|c|c|c|c|c|}
\hline & \multirow{2}{*}{$n$} & \multicolumn{2}{|l|}{ RFS } & \multicolumn{2}{|l|}{ OS } \\
\hline & & $\begin{array}{l}\text { Relative Risk } \\
\quad(95 \% \text { CI })\end{array}$ & $p$ & $\begin{array}{l}\text { Relative Risk } \\
\text { (95\% CI) }\end{array}$ & $p$ \\
\hline SE $E^{\text {invasive front }}$ & & & $<0.001$ & & $<0.001$ \\
\hline Low/negative & 58 & 1.000 & & 1.000 & \\
\hline High & 85 & 3.647 (1.912-6.955) & & $3.976(1.894-8.347)$ & \\
\hline LV invasion & & & 0.768 & & 0.939 \\
\hline Not identified & 39 & 1.000 & & 1.000 & \\
\hline Present & 104 & $0.911(0.490-1.694)$ & & $0.973(0.490-1.934)$ & \\
\hline Budding & & & 0.657 & & 0.882 \\
\hline Low & 36 & 1.000 & & 1.000 & \\
\hline High & 107 & $1.153(0.614-2.165)$ & & $0.949(0.476-1.893)$ & \\
\hline Invasion depth & & & 0.022 & & 0.030 \\
\hline $\mathrm{pT} 1+\mathrm{pT} 2$ & 26 & 1.000 & & 1.000 & \\
\hline $\mathrm{pT} 3+\mathrm{pT} 4$ & 117 & $3.774(1.314-10.840)$ & & $3.872(1.138-13.175)$ & \\
\hline LN metastasis & & & 0.833 & & 0.223 \\
\hline Not identified & 67 & 1.000 & & 1.000 & \\
\hline Present & 76 & 1.252 (0.747-2.099) & & $1.433(0.804-2.554)$ & \\
\hline Distant metastasis & & & 0.001 & & $<0.001$ \\
\hline M0 & 121 & 1.000 & & 1.000 & \\
\hline M1 & 22 & $2.592(1.455-4.618)$ & & 3.569 (1.935-6.523) & \\
\hline
\end{tabular}

RFS, recurrence-free survival; OS, overall survival; LV, lymphovascular invasion; LN, lymph node; CI, confidence interval. $p$ values were obtained by Cox proportional hazards analysis and $p<0.05$ are highlighted in bold.

\section{Discussion}

SE belongs to the flavoprotein monooxygenase family, which catalyzes a wide variety of oxidative reactions and epoxidation $[24,25]$ in cholesterol biosynthesis, and is differentially expressed in various human solid cancers. Alterations in metabolism are critical for the invasion and metastatic process of the tumor. However, the mechanisms by which these metabolic changes are controlled by the major drivers of the tumorigenic process remain elusive. Haider et al. confirmed SE as a metabolic driver in multiple cancers, demonstrating its association with poor prognosis and tumor hypoxia [26]. Thus, the $S Q L E$ gene may act as an oncogene, but whether it plays a role in colorectal cancer remains unknown. Herein, our study shows that SE expression was higher in the CRC tissues than in normal tissues. There is a significant correlation between the overexpression of SE and invasion depth, lymph node metastasis, and pTNM stage.

Cholesterol is an essential biological component required for the structural integrity of the cell membrane and lipid rafts and is also a precursor to steroid hormones. Cancer cells have an increased demand for cholesterol synthesis and metabolism, which is needed in tumor growth and progression. $\mathrm{SE}$ is an important cholesterol biosynthetic enzyme for the regulation of cellular cholesterol homeostasis in the endoplasmic reticulum. This enzyme is controlled by different mechanisms. One is through direct synthesis via the transcription of sterol regulatory element-binding proteins, which are activated in response to low sterol status, and bind sterol regulatory element consensus sequences [27]. In addition to transcriptional regulation, the rapid shutdown of cholesterol synthesis requires post-transcriptional control. SQLE is directly regulated by cholesterol itself [28,29]. Although the pathologic role of cholesterol in carcinogenesis is not fully understood and lacks consensus, recent reports show that intracellular de novo cholesterol biosynthesis is significantly upregulated in cancer cells, or the enzyme activity that catalyzes the rate-limiting step in de novo cholesterol biosynthesis is augmented in cancer cells, especially under hypoxia [30-33]. Cholesterol can be enzymatically modified to form metabolites, such as a family of oxysterols [cholesterol oxidation products (COP)]. COPs modulate the activity of signal transduction cascades [34-36]. For instance, 27 hydroxycholesterol (27-OHC) is a selective estrogen receptor modulator and an agonist of the liver $\mathrm{X}$ receptor. It is involved in tumor cell proliferation, EMT, tumor cell invasion, migration, and metastasis in breast cancer and prostatic 
cancer [37,38]. Therefore, it is necessary to study how SQLE contributes to the structural modification of the plasma membrane, and the formation of various COPs during tumorigenesis of CRC.

In the present study, we observed that there was a significant correlation between a high expression level of SE and the tumor budding status and invasion depth in the CRC. Tumor budding has been suggested to be associated with EMT, as evidenced by decreased or aberrant expression of E-cadherin $[39,40]$. The SE and E-cadherin protein expression pattern in the tumor budding of the CRC was determined by immunohistochemical analysis. SE expression significantly increased in the invasive front, especially in the tumor budding of the invasive front in contrast to the tumor center of the CRC. However, E-cadherin expression decreased in the corresponding infiltrating tumor budding cells. There was a reverse correlation between the expression level of SE and E-cadherin expression levels. These results imply that SQLE might be involved in the modulation of EMT, resulting in tumor invasion and progression. Although further studies are necessary to validate our findings, we suggest that SQLE may be an EMT-associated marker of the CRC. EMT is a reversible genetic program of trans-differentiation of epithelial cells into mesenchymal cells, and cancer cells acquire EMT/MET plasticity in the process of carcinogenesis and tumor progression. This phenomenon is affected by tumor cell metabolism and tumor micro-environmental factors including hypoxia and growth factors, and it permits tumor cells to involve the reorganization of the signaling network that governs tumor cell survival, proliferation, and homeostasis. Consistent with our results, Qin Y et al. reported that SQLE induces EMT by regulation of miR-133b in esophageal squamous cell carcinoma [17]. The loss of E-cadherin and the acquisition of a more mesenchymal phenotype have been shown to correlate with clinically poor prognosis and metastasis in various epithelial-derived solid tumors. Tumors with EMT gene signatures were more resistant to anti-cancer drugs and a significantly longer time to progress in patients enrolled in a randomized non-small cell lung cancer clinical trial [41]. Herein, our study shows that there is a significant correlation between a high expression level of SE and tumor budding, and a decrease in E-cadherin in the invasive front. Moreover, there is a significant correlation between high SE expression and tumor poor RFS, and worse OS in CRC patients. In CRC, tumor metastasis is the most frequent cause of treatment failure and is responsible for $90 \%$ of patient mortality. However, there is no molecular marker that can adequately predict the risk of tumor progression and metastasis. Taken together, the results suggest that SQLE may be considered a valuable biomarker for unfavorable prognosis, and could be the basis of a new strategy to target cholesterol metabolism for treating CRC.

\section{Conclusions}

The study aimed to obtain confirmative information for the clinicopathological significance and prognostic role of SE expression in human colorectal cancer. There was found to be a significant correlation between a high level of SE expression and LV invasion, tumor budding, invasion depth, lymph node metastasis, and pathologic TNM stage. In addition, a reverse correlation was found between SE and E-cadherin expression in the invasive front in the colorectal cancer tissue. High expression of SQLE can serve as a valuable biomarker for unfavorable prognosis and as a possible therapeutic target in CRCs

Author Contributions: Data curation, C.N.K.; methodology, J.H.K.; writing-original draft, J.H.K.; writing-review and editing, D.W.K.

Conflicts of Interest: The authors declare no conflict of interest.

\section{References}

1. Bray, F.; Ferlay, J.; Soerjomataram, I.; Siegel, R.L.; Torre, L.A.; Jemal, A. Global cancer statistics 2018: GLOBOCAN estimates of incidence and mortality worldwide for 36 cancers in 185 countries. CA Cancer J. Clin. 2018, 68, 394-424. [CrossRef] [PubMed]

2. Torre, L.A.; Siegel, R.L.; Ward, E.M.; Jemal, A. Global Cancer Incidence and Mortality Rates and Trends-An Update. Cancer Epidemiol. Biomark. Prev. 2016, 25, 16-27. [CrossRef] [PubMed] 
3. Tariq, K.; Ghias, K. Colorectal cancer carcinogenesis: A review of mechanisms. Cancer Biol. Med. 2016, 13, 120-135. [CrossRef]

4. Nagai, M.; Sakakibara, J.; Wakui, K.; Fukushima, Y.; Igarashi, S.; Tsuji, S.; Arakawa, M.; Ono, T. Localization of the squalene epoxidase gene (SQLE) to human chromosome region 8q24.1. Genomics 1997, 44, 141-143. [CrossRef]

5. Nagumo, A.; Kamei, T.; Sakakibara, J.; Ono, T. Purification and characterization of recombinant squalene epoxidase. J. Lipid Res. 1995, 36, 1489-1497.

6. Sotiriou, C.; Neo, S.Y.; McShane, L.M.; Korn, E.L.; Long, P.M.; Jazaeri, A.; Martiat, P.; Fox, S.B.; Harris, A.L.; Liu, E.T. Breast cancer classification and prognosis based on gene expression profiles from a population-based study. Proc. Natl. Acad. Sci. USA 2003, 100, 10393-10398. [CrossRef]

7. Liu, Y.; Sun, W.; Zhang, K.; Zheng, H.; Ma, Y.; Lin, D.; Zhang, X.; Feng, L.; Lei, W.; Zhang, Z.; et al. Identification of genes differentially expressed in human primary lung squamous cell carcinoma. Lung Cancer 2007, 56, 307-317. [CrossRef] [PubMed]

8. Zhang, H.Y.; Li, H.M.; Yu, Z.; Yu, X.Y.; Guo, K. Expression and significance of squalene epoxidase in squamous lung cancerous tissues and pericarcinoma tissues. Thorac. Cancer 2014, 5, 275-280. [CrossRef]

9. Helms, M.W.; Kemming, D.; Pospisil, H.; Vogt, U.; Buerger, H.; Korsching, E.; Liedtke, C.; Schlotter, C.M.; Wang, A.; Chan, S.Y.; et al. Squalene epoxidase, located on chromosome 8q24.1, is upregulated in 8q+ breast cancer and indicates poor clinical outcome in stage I and II disease. Br. J. Cancer 2008, 99, 774-780. [CrossRef]

10. Shkurnikov, M.Y.; Galatenko, V.V.; Lebedev, A.E.; Podol'skii, V.E.; Tonevitskii, E.A.; Mal'tseva, D.V. On statistical relationship between ADRA2A expression and the risk of breast cancer relapse. Bull. Exp. Biol. Med. 2014, 157, 454-458. [CrossRef] [PubMed]

11. Zhao, S.G.; Evans, J.R.; Kothari, V.; Sun, G.; Larm, A.; Mondine, V.; Schaeffer, E.M.; Ross, A.E.; Klein, E.A.; Den, R.B.; et al. The Landscape of Prognostic Outlier Genes in High-Risk Prostate Cancer. Clin. Cancer Res. 2016, 22, 1777-1786. [CrossRef] [PubMed]

12. Zhao, H.; Logothetis, C.J.; Gorlov, I.P. Usefulness of the top-scoring pairs of genes for prediction of prostate cancer progression. Prostate Cancer Prostatic Dis. 2010, 13, 252-259. [CrossRef]

13. Sui, Z.; Zhou, J.; Cheng, Z.; Lu, P. Squalene epoxidase (SQLE) promotes the growth and migration of the hepatocellular carcinoma cells. Tumour Biol. 2015, 36, 6173-6179. [CrossRef]

14. Kim, S.; Kon, M.; DeLisi, C. Pathway-based classification of cancer subtypes. Biol. Direct 2012, 7, 21. [CrossRef] [PubMed]

15. Brown, D.N.; Caffa, I.; Cirmena, G.; Piras, D.; Garuti, A.; Gallo, M.; Alberti, S.; Nencioni, A.; Ballestrero, A.; Zoppoli, G. Squalene epoxidase is a bona fide oncogene by amplification with clinical relevance in breast cancer. Sci. Rep. 2016, 6, 19435. [CrossRef] [PubMed]

16. Jardel, P.; Debiais, C.; Godet, J.; Irani, J.; Fromont, G. Ductal carcinoma of the prostate shows a different immunophenotype from high grade acinar cancer. Histopathology 2013, 63, 57-63. [CrossRef] [PubMed]

17. Qin, Y.; Zhang, Y.; Tang, Q.; Jin, L.; Chen, Y. SQLE induces epithelial-to-mesenchymal transition by regulating of miR-133b in esophageal squamous cell carcinoma. Acta Biochim. Biophys. Sin. 2017, 49, 138-148. [CrossRef] [PubMed]

18. Stopsack, K.H.; Gerke, T.A.; Sinnott, J.A.; Penney, K.L.; Tyekucheva, S.; Sesso, H.D.; Andersson, S.O.; Andren, O.; Cerhan, J.R.; Giovannucci, E.L.; et al. Cholesterol Metabolism and Prostate Cancer Lethality. Cancer Res. 2016, 76, 4785-4790. [CrossRef]

19. Washington, M.K.; Berlin, J.; Branton, P.; Burgart, L.J.; Carter, D.K.; Fitzgibbons, P.L.; Halling, K.; Frankel, W.; Jessup, J.; Kakar, S.; et al. Protocol for the examination of specimens from patients with primary carcinoma of the colon and rectum. Arch. Pathol. Lab. med. 2009, 133, 1539-1551. [CrossRef]

20. Prall, F. Tumour budding in colorectal carcinoma. Histopathology 2007, 50, 151-162. [CrossRef]

21. Wang, L.M.; Kevans, D.; Mulcahy, H.; O'Sullivan, J.; Fennelly, D.; Hyland, J.; O’Donoghue, D.; Sheahan, K. Tumor budding is a strong and reproducible prognostic marker in T3N0 colorectal cancer. Am. J. Surg. Pathol. 2009, 33, 134-141. [CrossRef] [PubMed]

22. Cho, S.J.; Kakar, S. Tumor Budding in Colorectal Carcinoma: Translating a Morphologic Score Into Clinically Meaningful Results. Arch. Pathol. Lab. Med. 2018, 142, 952-957. [CrossRef] [PubMed] 
23. Kim, J.H.; Park, M.Y.; Kim, C.N.; Kim, K.H.; Kang, H.B.; Kim, K.D.; Kim, J.W. Expression of endothelial cell-specific molecule-1 regulated by hypoxia inducible factor-1alpha in human colon carcinoma: Impact of ESM-1 on prognosis and its correlation with clinicopathological features. Oncol. Rep. 2012, 28, 1701-1708. [CrossRef]

24. Van Berkel, W.J.; Kamerbeek, N.M.; Fraaije, M.W. Flavoprotein monooxygenases, a diverse class of oxidative biocatalysts. J. Biotechnol. 2006, 124, 670-689. [CrossRef]

25. Joosten, V.; van Berkel, W.J. Flavoenzymes. Curr. Opin. Chem. Biol. 2007, 11, 195-202. [CrossRef]

26. Haider, S.; McIntyre, A.; van Stiphout, R.G.; Winchester, L.M.; Wigfield, S.; Harris, A.L.; Buffa, F.M. Genomic alterations underlie a pan-cancer metabolic shift associated with tumour hypoxia. Genome Biol. 2016, 17, 140. [CrossRef]

27. Nagai, M.; Sakakibara, J.; Nakamura, Y.; Gejyo, F.; Ono, T. SREBP-2 and NF-Y are involved in the transcriptional regulation of squalene epoxidase. Biochem. Biophys. Res. Commun. 2002, 295, 74-80. [CrossRef]

28. Gill, S.; Stevenson, J.; Kristiana, I.; Brown, A.J. Cholesterol-dependent degradation of squalene monooxygenase, a control point in cholesterol synthesis beyond HMG-CoA reductase. Cell Metab. 2011, 13, 260-273. [CrossRef] [PubMed]

29. Sharpe, L.J.; Brown, A.J. Controlling cholesterol synthesis beyond 3-hydroxy-3-methylglutaryl-CoA reductase (HMGCR). J. Biol. Chem. 2013, 288, 18707-18715. [CrossRef] [PubMed]

30. Clendening, J.W.; Pandyra, A.; Boutros, P.C.; El Ghamrasni, S.; Khosravi, F.; Trentin, G.A.; Martirosyan, A.; Hakem, A.; Hakem, R.; Jurisica, I.; et al. Dysregulation of the mevalonate pathway promotes transformation. Proc. Natl. Acad. Sci. USA 2010, 107, 15051-15056. [CrossRef] [PubMed]

31. Ginestier, C.; Monville, F.; Wicinski, J.; Cabaud, O.; Cervera, N.; Josselin, E.; Finetti, P.; Guille, A.; Larderet, G.; Viens, P.; et al. Mevalonate metabolism regulates Basal breast cancer stem cells and is a potential therapeutic target. Stem Cells (Dayton, Ohio) 2012, 30, 1327-1337. [CrossRef] [PubMed]

32. Azrolan, N.I.; Coleman, P.S. A discoordinate increase in the cellular amount of 3-hydroxy-3-methylglutaryl-CoA reductase results in the loss of rate-limiting control over cholesterogenesis in a tumour cell-free system. Biochem. J. 1989, 258, 421-425. [CrossRef] [PubMed]

33. Erickson, S.K.; Cooper, A.D.; Barnard, G.F.; Havel, C.M.; Watson, J.A.; Feingold, K.R.; Moser, A.H.; Hughes-Fulford, M.; Siperstein, M.D. Regulation of cholesterol metabolism in a slow-growing hepatoma in vivo. Biochim. Biophys. Acta 1988, 960, 131-138. [CrossRef]

34. Chen, H.W.; Kandutsch, A.A.; Waymouth, C. Inhibition of cell growth by oxygenated derivatives of cholesterol. Nature 1974, 251, 419-421. [CrossRef] [PubMed]

35. Bjorkhem, I. Five decades with oxysterols. Biochimie 2013, 95, 448-454. [CrossRef]

36. Olkkonen, V.M.; Beaslas, O.; Nissila, E. Oxysterols and their cellular effectors. Biomolecules 2012, 2, 76-103. [CrossRef]

37. Marwarha, G.; Raza, S.; Hammer, K.; Ghribi, O. 27-hydroxycholesterol: A novel player in molecular carcinogenesis of breast and prostate cancer. Chem. Phys. Lipids 2017, 207, 108-126. [CrossRef]

38. Nelson, E.R. The significance of cholesterol and its metabolite, 27-hydroxycholesterol in breast cancer. Mol. Cell. Endocrinol. 2018, 466, 73-80. [CrossRef]

39. Zlobec, I.; Lugli, A. Epithelial mesenchymal transition and tumor budding in aggressive colorectal cancer: Tumor budding as oncotarget. Oncotarget 2010, 1, 651-661. [CrossRef]

40. Slik, K.; Blom, S.; Turkki, R.; Valimaki, K.; Kurki, S.; Mustonen, H.; Haglund, C.; Carpen, O.; Kallioniemi, O.; Korkeila, E.; et al. Combined epithelial marker analysis of tumour budding in stage II colorectal cancer. J. Pathol. Clin. Res. 2019, 5, 63-78. [CrossRef]

41. Thomson, S.; Buck, E.; Petti, F.; Griffin, G.; Brown, E.; Ramnarine, N.; Iwata, K.K.; Gibson, N.; Haley, J.D. Epithelial to mesenchymal transition is a determinant of sensitivity of non-small-cell lung carcinoma cell lines and xenografts to epidermal growth factor receptor inhibition. Cancer Res. 2005, 65, 9455-9462. [CrossRef] [PubMed]

(C) 2019 by the authors. Licensee MDPI, Basel, Switzerland. This article is an open access article distributed under the terms and conditions of the Creative Commons Attribution (CC BY) license (http://creativecommons.org/licenses/by/4.0/). 